\title{
Updates in the treatment of ocular allergies
}

\author{
Osmo Kari' \\ K Matti Saari ${ }^{2}$ \\ 'Department of Allergology, Skin and \\ Allergy Hospital, Helsinki University \\ Central Hospital, Helsinki, Finland; \\ ${ }^{2}$ Department of Ophthalmology, \\ University of Turku, Turku, Finland
}

This article was published in the following Dove Press journal:

Journal of Asthma and Allergy

22 November 2010

Number of times this article has been viewed
Correspondence: Osmo Kari Department of Allergology, Skin and Allergy Hospital, Helsinki University Central Hospital, BP 160, Helsinki, $00029 \mathrm{HUCH}$, Finland $\mathrm{Tel}+3589$ 47I 86352

Mobile +358 407561404

Fax +358 9467782

Email osmo.kari@optokari.fi
Abstract: Allergic diseases have greatly increased in industrialized countries. About $30 \%$ of people suffer from allergic symptoms and $40 \%-80 \%$ of them have symptoms in the eyes. Atopic conjunctivitis can be divided into seasonal allergic conjunctivitis (SAC) and perennial allergic conjunctivitis (PAC). The treatment of SAC is simple; antihistamines, anti-inflammatory agents, or chromoglycate. In severe cases of SAC, subcutaneous or sublingual immunotherapy is helpful. PAC needs longer therapy, often year round, with mast cell stabilizers, antihistamines, and sometimes local steroids. Atopic keratoconjunctivitis is a more severe disease showing chronic blepharitis often connected with severe keratitis. It needs, in many cases, continuous treatment of the lid eczema and keratoconjunctivitis. Blepharitis is treated with tacrolimus or pimecrolimus ointment. Conjunctivitis additionally needs corticosteroids and, if needed, cyclosporine A (CsA) drops are administered for longer periods. Basic conjunctival treatment is with mast cell-stabilizing agents and in addition, antihistamines are administered. Vernal keratoconjunctivitis is another chronic and serious allergic disease that mainly affects children and young people. It is a long-lasting disease which commonly subsides in puberty. It demands intensive therapy often for many years to avoid serious complicating corneal ulcers. Treatment is mast cell-stabilizing drops and additionally antihistamines. In relapses, corticosteroids are needed. When the use of corticosteroids is continuous, CsA drops should be used, and in relapses, corticosteroids should be used additionally. Nonallergic eosinophilic conjunctivitis (NAEC) is a less known, but rather common, ocular disease. It affects mostly middle-aged and older women. The eye symptoms of NAEC are largely similar to those seen in chronic allergic conjunctivitis. Basic therapy is mast cell-stabilizing drops. Eosinophilic inflammation needs additional corticosteroids. In severe cases, CsA drops are recommended. Antihistamines should be avoided. It is important to recognize the different forms of allergic ocular diseases and to start the treatment early and intensively enough to avoid chronicity of the disease and accompanying tissue destruction.

Keywords: allergic conjunctivitis, allergic blepharitis, atopic keratoconjunctivitis, eosinophils, vernal keratoconjunctivitis

\section{Introduction}

Approximately one-third of the population is affected by some form of allergic disease worldwide, ${ }^{1}$ and ocular allergic symptoms are estimated to be present in $40 \%-80 \%$ of the affected individuals. ${ }^{2}$ The prevalence is greater in Western countries than in $\mathrm{Asia}^{3}$ or Africa.

Allergic eye inflammation is a localized allergic condition that is frequently associated with rhinitis and occasionally with asthma but often observed as the only or 
prevalent allergic sensitization. The symptoms and signs can manifest as conjunctivitis, blepharitis, blepharoconjunctivitis, or keratoconjunctivitis. The eye becomes red and itchy; there occurs lacrimation and slight discharge.

The allergic eye symptoms are mostly associated with atopy. The early phase reflects mast cell activation of allergic inflammation, whereas the late phase reaction is characterized by recruitment of inflammatory cells to the site of allergic inflammation. Initially, the visual acuity is usually normal. However, in some severe forms of allergic conjunctivitis and vernal keratoconjunctivitis (VKC), there may be visual impairment or change secondary to corneal damage or corneal curvature change. ${ }^{4}$ In the age group below 14 years, $44.7 \%$ of children with atopy had allergic rhinitis and $61 \%$ of them had conjunctivitis but only $5 \%$ presented with conjunctivitis alone. ${ }^{5}$ Chronic allergic eye disease should be differentiated from the nonallergic eosinophilic conjunctivitis (NAEC). 6,7

The main goal of the treatment of an allergic eye disease is to reduce the inflammation early and to prevent complications, which can threaten vision or cause dry eye. In some cases, the active therapy can prevent the development of allergic rhinosinusitis or even asthma. ${ }^{8}$

In this article, we present a new understanding of the pathomechanisms of ocular allergy and new treatment modalities that target the pathomechanisms of allergic eye diseases.

\section{Etiology}

Seasonal allergic conjunctivitis (SAC) and perennial allergic conjunctivitis (PAC) are caused by immunoglobulin E (IgE)-mediated environmental airborne allergens, such as grass and tree pollens, mites, molds, and animal dander. The minority of allergic eye diseases are of cell-mediated or mixed type, which may manifest solely as blepharitis, blepharoconjunctivitis, or keratoconjunctivitis. The usual causes of the cell-mediated type are cosmetics, nickel, or topical eye medication.

The exact incidences of work-related allergic eye diseases are lacking. There is a wide spectrum of organic and inorganic materials that can cause allergies. In most cases, they are linked to asthma, rhinitis, or dermatitis. Some workers may have only occupational eye symptoms. ${ }^{9}$

\section{Pathomechanisms}

The immediate types, SAC and PAC, are IgE-mediated diseases. The peaks of ocular signs and symptoms are related to histamine release from specifically activated mast cells after allergen exposure. ${ }^{10}$ Mast cells contain, for example, histamine and tryptase. De novo synthesis of other mediators like leukotriens and prostaglandins also immediately begins. Histamine and other mediators like neurotrophins are responsible for itching. ${ }^{11,12}$ Activation of vascular endothelial cells and fibroblasts by a single mast cell degranulation can mount a cascade of proinflammatory events that amplify the clinical inflammation. ${ }^{13}$ The influence of different mediators, histamine, tryptase, prostaglandins, and leukotrienes, ${ }^{4}$ is strongest after 10-15 min. The chemotactic factors released by mast cells are responsible for accumulation of eosinophils and neutrophils at the site of allergic inflammation. Eosinophils contain granules in which preformed cytokines are rapidly secreted depending on the cytokine stimuli, Th1 (interleukin [IL]-12, IL-27, and interferon [IFN]- $\gamma$ ), and Th2 (IL-4 and IL-13). ${ }^{14}$

Lymphocytes, both T and B cells, are important cells in allergic reactions. These are divided into $\mathrm{CD} 4^{+}$helper $\mathrm{T}$ cells (Th) and $\mathrm{CD}^{+}$killer T cells (Tk). CD4+ ${ }^{+}$Th cells are commonly divided into regulatory $\mathrm{T}$ (Treg) and $\mathrm{T}$ helper (Th) cells. Treg cells are defined as $\mathrm{CD}^{+} \mathrm{T}$ cells, which may suppress potentially deleterious activities of Th cells. Treg cells are very important, for example, in the suppression of allergic reactions. ${ }^{15}$ Th1-type T helper cells are activated in the classic delayed-type hypersensitivity reaction and in some autoimmune diseases. The activation of Th2 cells leads to the anaphylactic type of hypersensitivity reaction. ${ }^{14} \mathrm{~T}$ cells start and regulate the immune response. IL-4 has an essential role in differentiating Th cells to Th2 cells. The activated Th cells regulate the maturation of $\mathrm{B}$ lymphocytes to mature antibody-producing B cells and plasma cells. The maturation of B lymphocytes to IgE-producing cells requires in addition to IL-4 a direct contact between pre-B and Th cells.

The prerequisite for the immune reaction is that the antigen must be recognized and presented to the cells, which are responsible for the development of the immune response. ${ }^{14}$ The antigen-presenting cells (APCs) in the conjunctiva are the Langerhans cells (LCs), which present the antigen to allergenspecific T lymphocytes (CD4 ${ }^{+} \mathrm{T}$ cells). These secrete Th2 cytokines such as IL-4 (for IgE synthesis) and IL-5 (eosinophilic growth factor). When re-exposures to allergen occurs, it activates Th 2 cells to express Th2 cytokines. Simultaneously, it cross-links IgE, which is affixed to mast cell high-affinity receptors, and induces mast cell degranulation. ${ }^{15}$

The APCs have an important role, both direct and indirect, to control the expansion and function of $\mathrm{T}$ cells. They also 
initiate a CD8 cytotoxic T-cell response, which is responsible for various forms of autoimmunity and transplant rejection. ${ }^{16}$ Antigen (Ag)-specific T cells initiate the eosinophilic infiltration in the conjunctiva because allergic conjunctivitis is an Ag-specific disease and eosinophils do not have Ag-specific receptors. ${ }^{17}$

In the cell-mediated type of reaction (delayed type or type IV), $\mathrm{T}$ cells recognize the antigen and start the inflammatory reaction. Typical delayed-type reactions are contact dermatoconjunctivitis and Mantoux (tuberculin) reaction. Macrophages activated by Th cells destroy intracellular bacteria, but they also cause other delayed inflammatory reactions including the contact hypersensitivity of the skin and tuberculin reaction. These reactions reach their maximum in 24-72 $\mathrm{h}$.

\section{Diagnostics}

A good patient history and clinical examination are essential and can solve the nature of the eye disease in many cases. When the diagnosis is not clear, some laboratory examinations are needed. When an infection could be possible, bacterial and viral specimens are taken. By using the conjunctival brush cytology, it is possible to see, for example, typical epithelial changes in dry eyes. The spectrum of inflammatory cells can reveal the nature of the inflammation. An allergic inflammation is especially suspected if eosinophils are seen.

Tear fluid IgE can be measured. The local production is evident, but it shows only the free $\operatorname{IgE}$, which is not tissue bound.

Determination of inflammatory mediators like eosinophilic cationic proteins and cytokines may be helpful, but the determination is difficult and time consuming and thus not suitable for everyday practice.

When the patient history is clear and the symptoms are typical for SAC, the allergy tests are usually not needed. In suspected cases, where diagnosis is not clear, a basic skin prick test or specific serum IgE-determinations (ImmunoCAP ${ }^{\circledR}$; Phadia, Uppsala, Sweden) are recommended. A good allergy examination, especially in children, is needed. The total serum IgE itself is not enough to prove ocular allergy.

When the patient has also a suspected allergic blepharitis, the epicutan tests should be done. If contact allergy to eyedrops is suspected, an epicutan test should be done with the drops used (sometimes also as prick test).

When there is a strong doubt about allergy or an immunotherapy is planned, an ophthalmic challenge test can be made. It should be done with standardized water-soluble allergen extracts (SQ-quality; ALK-Abello, Copenhagen, Denmark). The test should be done with the patient always blinded in one eye and the diluent as placebo in the other eye. ${ }^{18}$ In occupational allergy, some substances can be tested, but in most cases, the direct tests are not possible.

\section{Treatment targets the pathomechanisms of ocular allergies}

Steroid preparations, antihistamines, and mast cell-stabilizing drugs have long been the mainstay of the therapy. In mild conditions, antihistamines and mast cell-stabilizing drugs are sufficient. Chronic, severe allergic eye disorders like VKC and atopic blepharoconjunctivitis (ABC) are the challenge for treatment. To avoid the serious ocular side effects of long-term corticosteroid treatment, we have, nowadays, the opportunity to use a new class of anti-inflammatory agents in corticosteroid replacing therapy, namely, calcineurin $(\mathrm{Cn})$ inhibitors.

$\mathrm{Cn}$ has an important role in the immune response. Inflammatory cells play a role in producing and maintaining skin inflammation in atopic dermatitis. They include T cells, mast cells, basophils, eosinophils, and LCs. Antigen presentation by LCs leads to activation of T cells. The high-affinity receptor for $\operatorname{IgE}$ (FceR1) on the surface of LCs binds peptide antigens by means of free $\mathrm{IgE}$ present in the inflammatory infiltrate. T cells are activated through a calcium-dependent pathway in which $\mathrm{Cn}$ dephosphorylates the nuclear factor of activated T cell protein (NF-ATp). NF-ATp then migrates to the T cell, where it leads to the transcription of IL-2 and other cytokines. Besides the role of $\mathrm{Cn}$ in $\mathrm{T}$ cells, $\mathrm{Cn}$ plays a role in various tissues and also in the skin. ${ }^{19-22}$

$\mathrm{Cn}$ inhibitors are capable of inducing local immunosuppression. $\mathrm{Cn}$ is the target of the immunosuppressive drugs cyclosporine A (CsA), tacrolimus ( $\operatorname{Trl})$, and pimecrolimus (Prl). The Cn inhibitors CsA, Trl, and Prl are used for the treatment of dermatological diseases, such as psoriasis and atopic eczema. ${ }^{20,22} \mathrm{CsA}$ is also effective in controlling ocular allergic inflammation by blocking Th2-lymphocyte proliferation and IL-2 production. It also reduces eosinophils' chemotaxis via inhibition of IL-5 production. Earlier studies have shown that the FK506-binding protein also inhibits the release of inflammatory mediators from mast cells and basophils. ${ }^{19} \mathrm{We}$ have shown that for the eyes suffering from $\mathrm{ABC}$, topical $\mathrm{Trl}$ was very effective in reducing inflammatory cells, especially eosinophils, as shown in conjunctival cytology. ${ }^{23}$ 
Since 1990, our first-line therapy in severe atopic blepharitis has been $\mathrm{Cn}$ inhibitor Trl or weaker Prl ointment. In severe and chronic allergic conjunctivitis, the continuous corticosteroid therapy should be replaced with $\mathrm{Cn}$ inhibitor drops $\mathrm{CsA}$ or $\mathrm{Trl}$, if possible. In therapy-resistant, severe allergic conjunctivitis or rhinoconjunctivitis, the immunotherapy should be started early to prevent complications or even the development of asthma. With the early treatment, the quality of life will be improved as does the patients' therapeutic compliance.

Allergen-specific immunotherapy (SIT) is highly effective in the treatment of patients with severe allergic conjunctivitis/rhinoconjunctivitis or asthma and is recommended by World Health Organization as an essential part of allergy management strategy. SIT involves the administration (usually subcutaneous) of increasing doses of allergen in order to achieve a hyposensitization. Monthly vaccinations lasting for 3 years are demanding for the patient. This therapy may have side effects, even anaphylactic reactions. Therefore, in recent years, other administration routes have been pursued. Sublingual immunotherapy (SLIT) with daily administration at least for 3 years is a new promising and safe method of SIT. Both methods gradually induce a tolerance and decrease the symptoms and the need of medication, thus improving the quality of life. The duration of this effect is about 10 years in subcutaneous immunotherapy (SCIT), and we can assume that it lasts about the same time with SLIT.

The mechanism of action in SLIT and SCIT is the same. The phenotype of $\mathrm{T}$ cells is shifted from Th2 prevalence with production of cytokines, interleukins (IL-4, IL-5, IL-13, IL-17, and IL-32), to Th1-type response, thus increasing IFN- $\gamma$ and IL- 2 production and reducing Th 2 activity. This is what is believed to happen through anergy or tolerance. ${ }^{24}$ $\mathrm{T}$-cell tolerance is characterized by the generation of allergen-specific Treg producing IL-10 and transforming growth factor- $\beta$ with immunosuppressant or regulatory properties.

Another method of immunomodulation is anti-IgE therapy. The anti-IgE antibody (omalizumab) has its effect by binding to IgE that is not bound to mast cells and inhibits it from binding to mast cells. ${ }^{25}$ The target diseases are allergic rhinoconjunctivitis and asthma. The subcutaneous injections are given every 4 weeks or more frequently.

With early, intensive, and long-enough therapy, the destructive inflammatory processes can be slowly turned off, and in best cases, the therapy can be stopped or at least reduced.

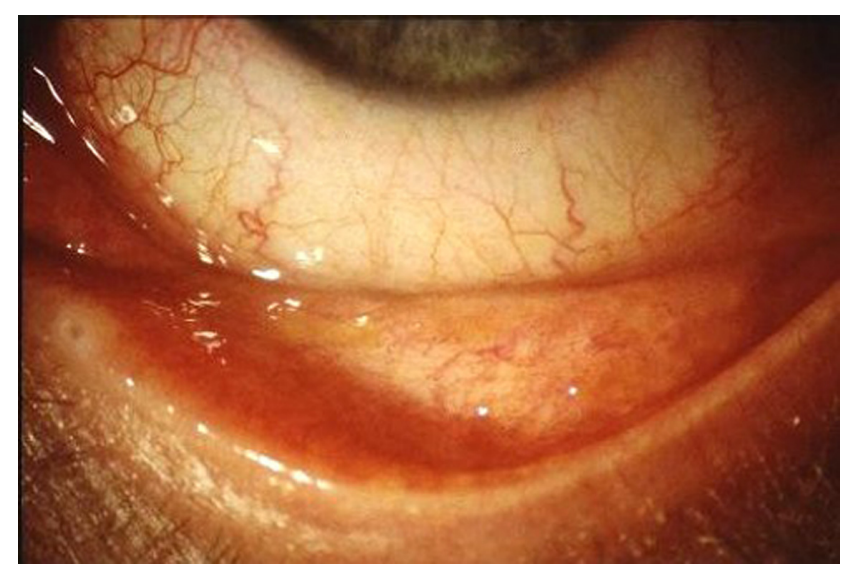

Figure I Acute allergic conjunctivitis.

\section{Acute allergic conjunctivitis}

SAC is the most common allergic disease in the eye (Figure 1). It is also called hay fever conjunctivitis. SAC is usually caused by pollen, and the symptoms are limited to the season. Some patients may have exacerbations of symptoms around the year, for example from animals, mites, and more rarely foods or molds.

Itching of the eyes is the most characteristic symptom of SAC. Other symptoms include tearing, burning sensation, and photophobia. SAC is usually bilateral. The signs consist of mild papillary hypertrophy of the tarsal conjunctiva, redness, lid and/or conjunctival edema, and chemosis.

It is important that the therapy should be started immediately, sufficiently, and for long enough, that is, throughout the season until all the symptoms have disappeared. The goal is to prevent transformation of SAC to a chronic inflammation. It is important to also treat the possible concomitant rhinitis or asthma symptoms.

In the treatment of SAC, antihistamines are effective. Tablets are more effective than drops in coincident rhinitis symptoms. Sometimes in the acute stage, local corticosteroids are needed. The treatment should be continued with mast cell stabilizers including sodium chromoglycate, nedocromil, or lodoxamide eyedrops (Table 1). There may be also a mild lid eczema, which can be treated with a short-term corticosteroid ointment.

In most cases, SAC is not serious. However, it may be very disturbing to patients, can affect their quality of life, and can have significant socioeconomic impact. In more serious cases where an appropriate local therapy has failed, immunotherapy is a good choice. Until recently, only SCIT with injections was available, ${ }^{26}$ but now, a new and more comfortable option, SLIT, has become available. ${ }^{27-29}$ In both these forms of immunotherapy, the ocular symptoms usually 
Table I Topical treatment schedule for eosinophilic allergic and eosinophilic nonallergic conjunctivitis

\begin{tabular}{|c|c|c|}
\hline Treatment & Allergic & Nonallergic \\
\hline Antibiotics & No & In the beginning \\
\hline $\begin{array}{l}\text { Corticosteroids or } \\
\text { corticosteroids-antibiotics }\end{array}$ & $\begin{array}{l}\text { Not usually or short- } \\
\text { term }\end{array}$ & $\begin{array}{l}\text { First step/later } \\
\text { when symptoms } \\
\text { persist }\end{array}$ \\
\hline Antihistamines & Yes & $\begin{array}{l}\text { Not usually } \\
\text { or short term }\end{array}$ \\
\hline Mast cell stabilizers & Yes & Yes \\
\hline Astringents & Not usually & No \\
\hline Lubricants & Sometimes & Yes \\
\hline Immunotherapy & In severe cases & No \\
\hline Nonsteroidals (NSAID) & Seldom & Yes \\
\hline $\begin{array}{l}\text { Immunosupressants } \\
\text { (cyclosporine and tacrolimus) }\end{array}$ & No & Yes \\
\hline $\begin{array}{l}\text { Duration of topical } \\
\text { treatment }\end{array}$ & Short term & Long term \\
\hline
\end{tabular}

subside first. The effect of SCIT usually lasts for 7-10 years. The SCIT must be started outside the season. It demands regular monthly injections, which must be started at lower concentrations and increased gradually to the maintenance doses. Anaphylactic reactions are possible, and therefore the injection must be given in places where the staff is educated to treat anaphylactic reactions.

SLIT is available at least to grass pollens, for example, timothy, ragweed, and to birch pollen, house dust mite, and latex. The advantage of SLIT is that the tablets can be taken at home. The tablets can be taken daily for 3 months (preseasonal) to 3 years. SLIT is not as effective as SCIT, but randomized, double-masked studies are lacking. Side effects of SLIT are usually harmless, but some anaphylactic reactions have been described in the literature..$^{30}$ The duration of the effect after cessation of SLIT is not known. In severe and polysensitized rhinoconjunctivitis cases, a combination of SLIT or SCIT with anti-IgE antibody therapy (omalizumab) may be beneficial. ${ }^{31}$

\section{Chronic allergic conjunctivitis PAC}

The allergy panel of patients with PAC (Figure 2) often shows allergy to animals and mites. The symptoms and signs are much the same as in SAC, but they are usually milder. This condition affects all age groups but mostly young and middle-aged people of both sexes.

PAC is often connected with dry eye, which has an impact on therapy. The therapy should be started without delay, intensive enough, and for long enough. Milder cases can be treated with topical mast cell stabilizers, which should be

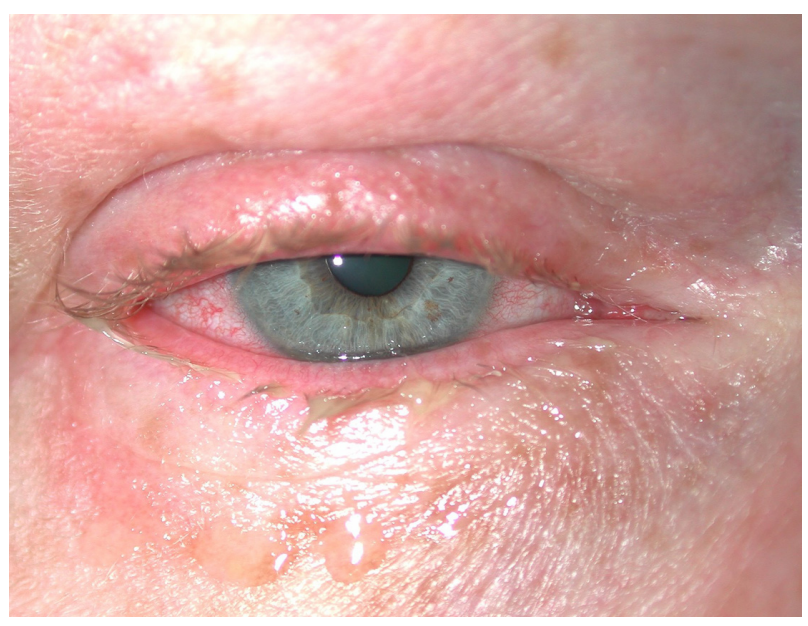

Figure 2 Chronic allergic conjunctivitis.

without preservatives. A common preservative in topical medications, benzalkonium chloride, may occasionally cause ocular allergies. More harmful is its toxicity to the inflamed conjunctiva, and it may worsen the already existing dry eye. Sodium chromoglycate or lodoxamide drops 3-4 times daily may be helpful in mild dry eye symptoms. Antihistamines are not suitable for long-term use because they can worsen or even cause dry eye. However, they can be used for short terms as an additive medication. In more severe cases, topical steroids are needed for short terms as pulse therapy. Pre-existing other allergic symptoms including rhinitis, asthma, or atopic dermatitis should be treated appropriately.

\section{$A B C$}

$A B C$ (Figure 3) is a serious and often chronic eye disease (Figure 4). The patients typically have atopic eczema in the face and eyelids. This disease more often affects boys and men. The patients with $\mathrm{ABC}$ often have high serum IgE levels, which may be several thousand IU per milliliter. These patients are in many cases multiallergic, that is, they have several positive skin prick tests to common environmental allergens.

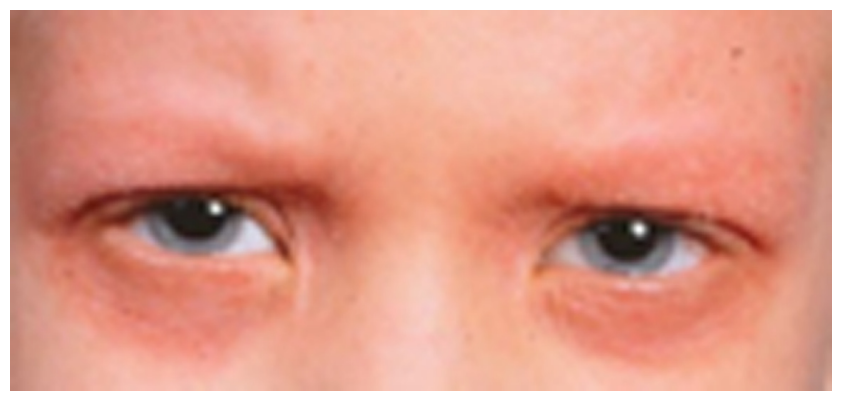

Figure 3 Atopic blepharoconjunctivitis in a child. 


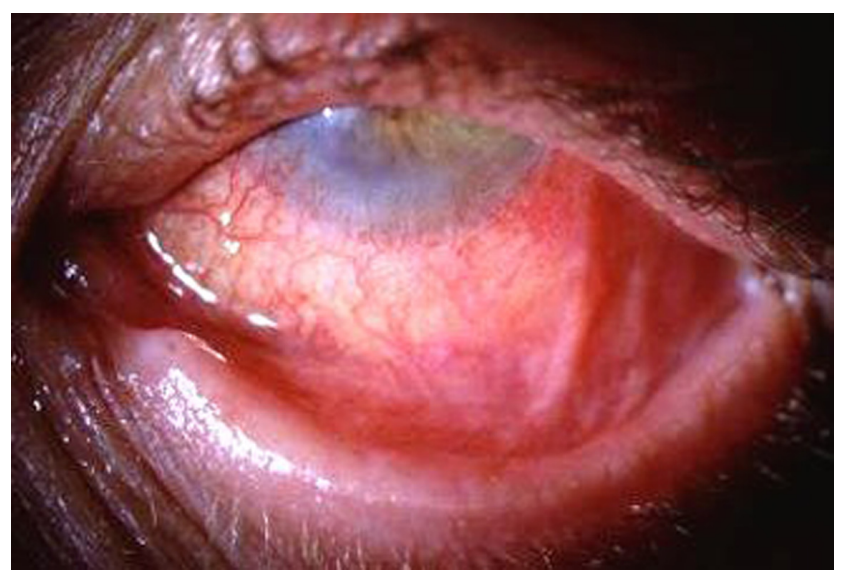

Figure 4 Severe atopic blepharoconjunctivitis.

The symptoms of $\mathrm{ABC}$ include intense itching, photophobia, epiphora, and occasionally blurred vision. The signs consist of red and swollen lids often with rhagades, lost eyelashes, and red and swollen tarsal conjunctiva with papillary hypertrophy. In worst cases, a serious corneal ulcer may lead to vision-disturbing scars or even to ocular penetration. These ulcers are dangerous because in $\mathrm{ABC}$, the skin of the eyelids and the conjunctiva mostly show Staphylococcus aureus infection.

The topical treatment for $\mathrm{ABC}$ consists of different steroid preparations. Now a new product, calcineurin inhibitor tacrolimus, which was first used for the treatment of atopic dermatitis, has been shown to be very useful in the treatment of $\mathrm{ABC}$. We are among the first to use Trl ointment in the treatment of atopic lid eczema 10 years ago. ${ }^{23}$ Since then we have seen very good results without any serious side effects in this treatment. ${ }^{32}$

The treatment of $\mathrm{ABC}$ must be divided into two parts: lid skin care and treatment of conjunctivitis. In short-term lid therapy, corticosteroid ointments are a good choice. In long-term treatment, the side effects of corticosteroids are obvious: possible corticosteroid-induced glaucoma, cataract, or atrophy of the lid skin. With $\operatorname{Trl} 0.03 \%$ ointment or with another $\mathrm{Cn}$ inhibitor 1\% Prl, the treatment is safe without any serious side effects, even in children. ${ }^{23,32,33}$ The Trl ointment is usually applied to the lids at night for 2 weeks or more until the eczema has healed. When the symptoms have subsided, the treatment can be stopped or it can be continued in milder cases for 2-3 times a week. The remission period is substantially longer than that with corticosteroid treatment. Trl ointment seems to be very safe and can be continued for a longer time regularly or intermittently. Weaker Prl at the beginning must be applied 2 times daily but later on once daily is sufficient.

\section{VKC}

VKC (Figure 5) is a relatively rare chronic disease, which mainly affects children and young adolescents. The majority of patients are boys, with a male:female ratio of $3: 1$. The disease usually begins at the age of 6-10 years. Only about $60 \%$ are atopic. VKC is often complicated by keratitis and corneal ulcers, which may cause visual disability.

Main symptoms of VKC are intense itching and photophobia. The signs include redness, lid swelling, inflammatory ptosis, ropy discharge, and eosinophilic granulomas as giant papillae on the upper tarsal plate. The conjunctival cytolology in patients with VKC shows a great amount of eosinophils and other inflammatory cells.

The treatment of VKC may last from months to several years depending on severity of the disease. The mainstay of the therapy is mast cell-stabilizing drops. In relapses, a topical corticosteroid pulse therapy is needed. When the need of corticosteroids is almost continuous, CsA eyedrops $0.05 \%$ or $0.1 \%$ are needed. CsA $0.1 \%$ aqueous ophthalmic solution twice daily is an effective and safe topical medication in the treatment of VKC. ${ }^{34}$ We have used the same strength of CsA solution for children in Helsinki University Skin and Allergy Hospital for 10 years without any serious side effects (unpublished data). In Japan, Trl ophthalmic suspension $0.1 \%$ twice daily was very effective in the treatment of severe allergic conjunctivitis. ${ }^{35} \mathrm{We}$ have used $\operatorname{Trl} 0.01 \%$ eyedrops in ricin oil vehicle twice daily in the treatment of severe allergic conjunctivitis both for children and adults. This treatment was effective, but many of our patients showed marked side effects including burning and irritation. The ricin oil vehicle may have caused these symptoms especially in patients with a dry eye.

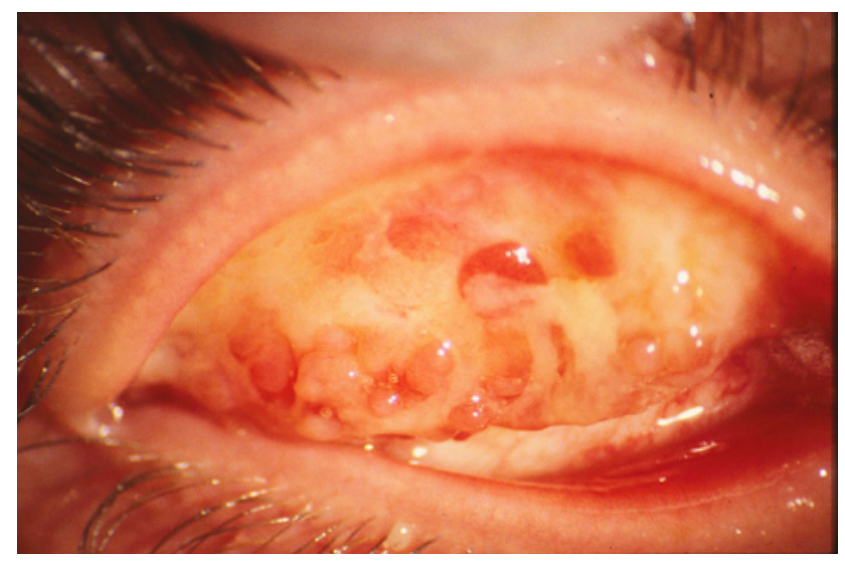

Figure $\mathbf{5}$ Vernal keratoconjunctivitis. 


\section{NAEC}

NAEC (Figure 6) seems to be poorly known in clinical practice as the presence of eosinophils is usually regarded as a sign of allergy. ${ }^{6,76}$ The condition may be analogous to the nonallergic eosinophilic rhinitis ${ }^{6,37}$ and nonallergic eosinophilic asthma. ${ }^{38}$ The majority of patients are middleaged or older women. Their skin prick tests are negative, serum IgE is normal, and they have no atopic eczema. However, these patients often have dry eye.

The symptoms of NAEC include itching, foreign body sensation, lacrimation, slight discharge, and minimal lid swelling. Signs consist of eosinophilia in conjunctival cytology (Figure 7), at least (1+) on the semiquantitative scale. ${ }^{39}$

In the treatment of NAEC, we have successfully used hydrocortisone-containing eyedrops for 1-2 weeks and continued with topical mast cell-stabilizers including chromoglycate, nedocromil, or lodoxamide or with nonsteroidal anti-inflammatory drugs including topical diclofenac. Because of the common coexisting dry eye, the preservativefree mast cell-stabilizing agents are recommended. Longterm use of topical or systemic antihistamines should be avoided because of their drying effects. Additive short-term use of corticosteroids is often needed. Moistening drops are added as needed. In severe cases, CsA eyedrops can be used (Table 1). Due to the chronicity of NAEC, the duration of the therapy varies from months to years.

\section{Contact allergic blepharoconjunctivitis}

Contact allergic blepharitis (Figure 8) and contact allergic blepharoconjunctivitis $(\mathrm{CABC})$ are common. In a

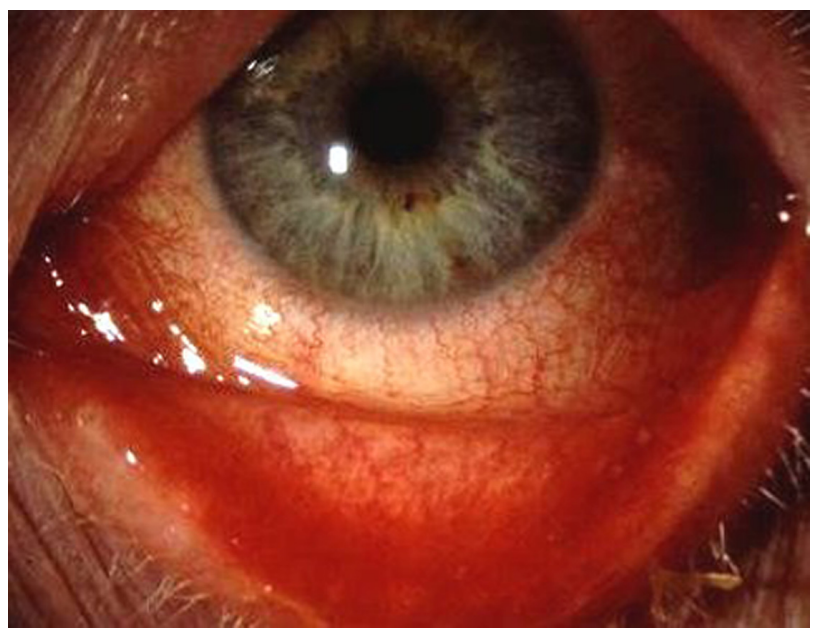

Figure 6 Nonallergic eosinophilic conjunctivitis.
German study, the predominant causes were allergic contact dermatitis (44\%), atopic eczema (25\%), airborne contact dermatitis (10\%), and irritant contact dermatitis $(9 \%){ }^{40}$

Contact dermatoconjunctivitis is a typical contact T-cell-mediated delayed hypersensitivity reaction to haptens, which become immunogenic only after they bind to tissue protein. Typical delayed type of allergies, the symptoms of which may be only in the eyelids, are nail lacquer and mascara allergies and the components of eyedrops and ointments. The most common place in nail lacquer allergies is just the eyelids. The sensitizer is often the toluensulfonamide-formaldehyde resin. The main allergen in mascara is natural resin, which is used in most mascara as adhesive. The lid mascara often contains nickel and cobalt (blue color), which may cause lid eczema for those who are already sensitized and the mascara may also itself sensitize the users.

All eyedrops and ointments contain allergens, for example antibiotics including neomycin, framycetin, sulfa, chloramphenicol, and (oxy) tetracycline; glaucoma medications, including pilocarpine, beta blockers, brimonidine, apraclonidine, dorzolamide, and prostaglandin derivatives; local anesthetics; antihistamines; anticholinergics; the preservatives benzalkonium chloride and thimerosal; mydriatics including scopolamine, atropine, tropicamide, phenylephrine hydrochloride, and cyclopentolate hydrochloride. These agents can cause very angry allergic reactions which may last a long time and cause, especially in glaucoma therapy, a common intolerance to all topical glaucoma medication. In addition, contact lens care solutions, for example chlorhexidine and papain, can cause

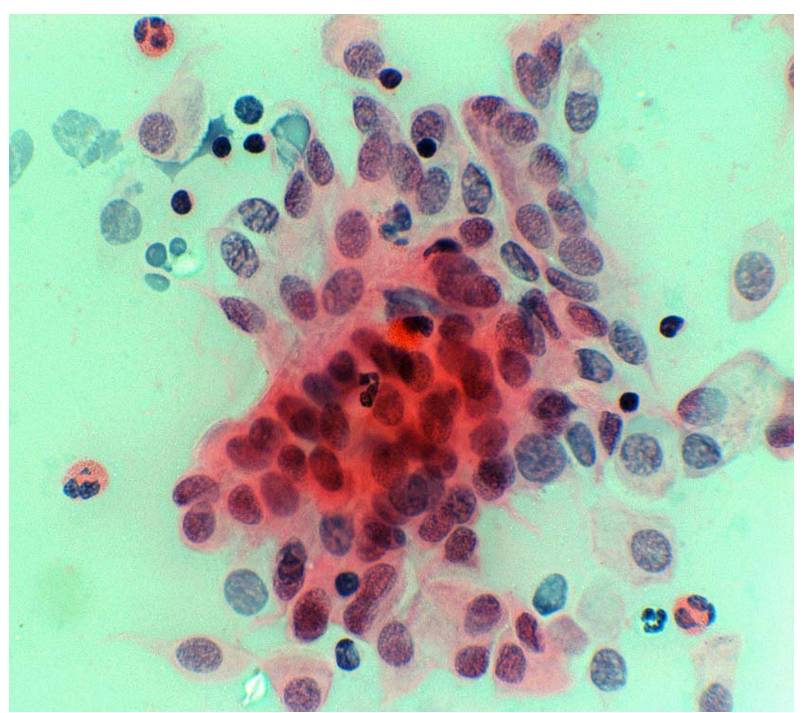

Figure 7 Conjunctival cytology 


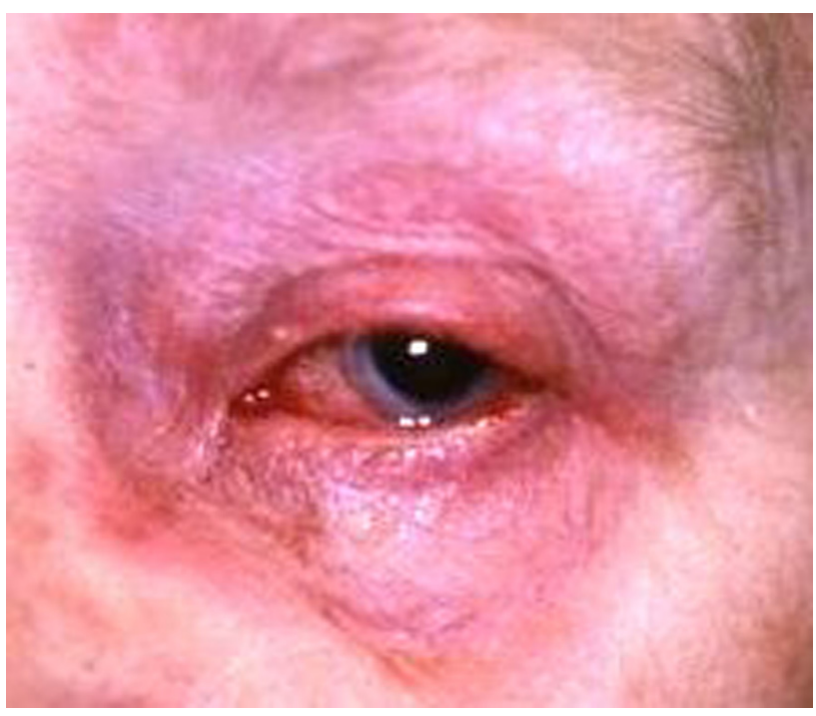

Figure 8 Contact allergic blepharoconjunctivitis (pilocarpine eyedrops).

robust allergic reactions. These allergic reactions manifest almost always as blepharoconjunctivitis, which means that besides lid eczema, there is also conjunctivitis.

Many different substances can cause symptoms both in the eyelids and in other skin parts of the body, but the thin skin of the eyelids is the most sensitive. Frames of eyeglasses that contain plastics and metal may cause eczema both in the contact area and lid and face.

Delayed type of allergy is caused by many components that spread as aeroallergens and can cause lid or face eczema. These allergens include rubber chemicals, some greenhouse plants, and the lactones of composites.

Skin prick tests and epicutan tests are diagnostics of lid eczema. It is important to test also with the patient's own materials, because the standard test series cover poorly the allergens which cause lid eczema. Atopic and seborrheic lid eczema (Figure 9) resemble each other. Skin tests help to make the right diagnosis.

In the treatment of $\mathrm{CABC}$, it is most important to clarify the causing agent and to eliminate it. Allergic lid eczema heals also without therapy when the allergen is avoided. The healing process may be sped up by using mild corticosteroid ointment on the lids for a few days. Sometimes antihistamines are needed for a short time against intense itching.

Atopic blepharitis is often chronic and needs longer therapy. In the treatment, corticosteroid ointments can be used for a short time. In chronic atopic blepharitis, we can now use a very effective and safe corticosteroid-replacing therapy, Trl ointment $\left(\right.$ Protopic $\left.^{\circledR}\right)$. It has two concentrations: $0.1 \%$ and $0.03 \%$. We have used during the last 10 years $\operatorname{Trl} 0.03 \%$ ointment on the lids in children without any serious side effects. It does not cause skin atrophy, cataract, or glaucoma as long-term corticosteroid treatment does. ${ }^{18,26}$ Weaker $\operatorname{Prl}\left(\right.$ Elidel $\left.^{\circledR}\right)$ in $1 \%$ concentration is another corticosteroid-replacing therapy for lid eczema.

\section{Summary}

Allergic conjunctivitis is common and occurs generally in both eyes. It may appear as the first step of the allergic cascade. It should be treated early, effectively, and for long enough to prevent worsening of the eye symptoms and spreading of the allergic inflammation to the airways.

In the treatment, we may raise the tolerance against natural allergens with SCIT or SLIT. The other way is to regulate and minimize the tissue destruction, especially in chronic allergic inflammation, with corticosteroid replacing immunomodulating therapies.

In severe SAC, SCIT or SLIT are recommended. The more common slight forms are treated with antihistamines and/or mast cell-stabilizing agents. It is important to treat simultaneously often concomitant rhinitis or asthmatic symptoms.

In chronic allergic conjunctivitis and NAEC, mast cell-stabilizing agents are recommended. Preservative-free drops should be preferred. The often concomitant dry eye often becomes worse with long-standing antihistamine therapy. Short-term corticosteroids are often needed additionally. More severe cases may need $\mathrm{Cn}$ inhibitors such as CsA drops. Dry eye often needs additional artificial tears.

In the more severe forms of $\mathrm{VKC}$ and $\mathrm{ABC}$, the inflammation needs often long-standing therapy for which corticosteroid-replacing therapies are recommended. In VKC, corticosteroids should be replaced with Cn inhibi-

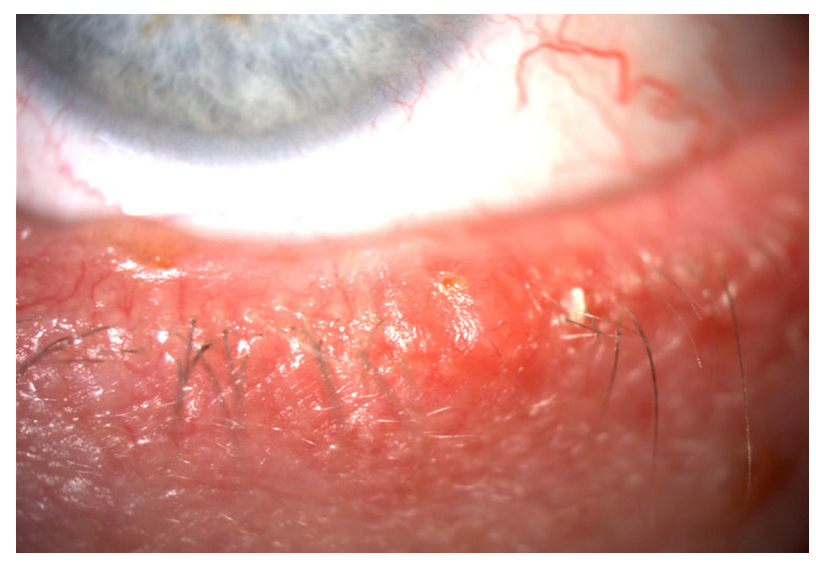

Figure 9 Seborrheic blepharitis. 
tors such as CsA drops. The mainstay of therapy is mast cell-stabilizing agents. Antihistamines alone are not recommended, but they can be used periodically combined with mast cell-stabilizing agents. Sometimes additional short-term steroid therapy is needed. Severe ABC is treated like VKC, but ABC patients may need lubricating drops additionally for dry eye.

The concomitant and often severe blepharitis must be treated simultaneously with corticosteroid-replacing $\mathrm{Cn}$ inhibitors. $\operatorname{Trl} 0.03 \%$ ointment once daily is very effective. Weaker Prl 1\% is applied at the beginning twice daily; later, once daily is sufficient. Chronic atopic blepharitis should be treated in the first line with $\mathrm{Cn}$ inhibitors, which can be used intermittently or continuously. If these are not tolerated, minimized corticosteroid therapy can be used.

\section{Disclosure}

The authors declare no conflicts of interest.

\section{References}

1. Key B. Allergy and allergic diseases. Part I. N Engl J Med. 2001;344: 30-37.

2. Ono SJ, Abelson MB. Allergic conjunctivitis update on pathophysiology and prospects for future treatment. J Allergy Clin Immunol. 2005;115(1): 118-122.

3. Hussain A, Awan H, Khan MD. Prevalence of non-vision-impairing conditions in a village in Chakwal district, Punjab, Pakistan. Ophthalmic Epidemiol. 2004;11(5):413-426.

4. Leonardi A, Motterle L, Bortolotti M. Allergy and the eye. Clin Exp Immunol. 2008;153 Suppl 1:17-21.

5. Ibáñez MD, Garde JM. Allergy in patients under fourteen years of age in Alergológica. J Investig Allergol Clin Immunol. 2009;19 Suppl 2: 61-68.

6. Saari KM, Kari O, Haahtela T. Nonallergic eosinophilic conjunctivitis. Expert Rev Ophthalmol. 2007;2(3):331-333.

7. Kari O, Haahtela T, Laine P, et al. Cellular characteristics of nonallergic eosinophilic conjunctivitis. Acta Ophthalmol. 2010;88(2): 245-250.

8. Reitamo S, Remitz A, Haahtela T. Hit early and hit hard in atopic dermatitis and not only in asthma. Allergy. 2009;64(4): 503-504.

9. Malo J-L, Lemiére C, Desjardins A, Cartier A. Prevalence and intensity of rhinoconjunctivitis in subjects with occupational asthma. Eur Respir J. 1997;10(7):1513-1515.

10. Irani AM. Ocular mast cells and mediators. Immunol Allergy Clin North Am. 2008;28(1):25-42, v.

11. Ikoma A. Analysis of the mechanism for the development of allergic skin inflammation and the application for its treatment: mechanisms and management of itch in atopic dermatitis. J Pharmacol Sci. 2009; 110(3):265-269

12. Scuri M, Samsell L, Piedimonte G. The role of neurotrophins in inflammation and allergy. Inflamm Allergy Drug Targets. 2010;9(3): 173-180.

13. McGill JI, Holgate ST, Church MK, Anderson DF, Bacon A. Allergic eye disease mechanisms. Br J Ophthalmol. 1998;82(10): 1203-1214.

14. Spencer LA, Szela CT, Perez SA, et al. Human eosinophils constitutively express multiple Th1, Th2 and immunoregulatory cytokines that are secreted rapidly and differentially. J Leukoc Biol. 2009;85(1): $117-123$.
15. Corthay A. How do regulatory T cells work? Scand J Immunol. 2009; 70(4):326-336.

16. Gill D, Tan PH. Induction of pathogenic cytotoxic T lymphocyte tolerance by dendritic cells: a novel therapeutic target. Expert Opin Ther Targets. 2010;14(8):797-824.

17. Fukushima A, Ozaki A, Fukata K, Ishida W, Ueno H. Ag-specific recognition, activation, and effector function of $\mathrm{T}$ cells in the conjunctiva with experimental immune-mediated blepharoconjunctivitis. Invest Ophthalmol Vis Sci. 2003;44(10):4366-4374.

18. Kari O, Salo OP, Halmepuro L, Suvilehto K. Tear histamine during allergic conjunctivitis challenge. Graefes Arch Clin Exp Ophthalmol. 1985;223(2):60-62.

19. de Paulis A, Stellato C, Cirillo R, Ciccarelli A, Oriente A, Marone G. Anti-inflammatory effect of FK-506 on human skin mast cells. J Invest Dermatol. 1992;99(6):723-728.

20. Reynolds NJ, Al-Daraji WI. Calcineurin inhibitors and sirolimus: mechanism of action and applications in dermatology. Clin Exp Dermatol. 2002;27(7):555-561.

21. Aramburu J, Heitman J, Crabtree GR. Calcineurin: a central controller of signalling in eukaryotes. EMBO Rep. 2004;5(4):343-348.

22. Reitamo S. Tacrolimus: a new topical immunomodulatory therapy for atopic dermatitis. J Allergy Clin Immunol. 2001;107(3):445-448.

23. Virtanen HM, Reitamo S, Kari M, Kari O. Effect of $0.03 \%$ tacrolimus ointment on conjunctival cytology in patients with severe atopic blepharoconjunctivitis: a retrospective study. Acta Ophtalmol Scand. 2006;84(5):693-695.

24. Frati F, Scurati S, Puccinelli P, et al. Development of sublingual allergy vaccine for grass pollinosis. Drug Des Devel Ther. 2010;4:99-105.

25. Okubo K, Nagakura T. Anti-IgE antibody therapy for Japanese cedar pollinosis: omalizumab update. Allergol Int. 2008;57(3):205-209.

26. Abramson MJ, Puy RM, Weiner JM. Injection allergen immunotherapy for asthma. Cochrane Database Syst Rev. 2010;8:CD001186.

27. Skoner D, Gentile D, Bush R, Fasano MB, McLaughlin A, Esch RE. Sublingual immunotherapy in patients with allergic rhinoconjunctivitis caused by ragweed pollen. J Allergy Clin Immunol. 2010;125(3): 660-666.

28. Malling H-J, Montagut A, Melac M, et al. Efficacy and safety of 5-grass pollen sublingual immunotherapy tablets in patients with different clinical profiles of allergic rhinoconjunctivitis. Clin Exp Allergy. 2009; 39(3):387-393.

29. Canonica GW, Bousquet J, Casale T, et al. Sub-lingual immunotherapy: World Allergy Organization position paper 2009. Allergy. 2009;64 Suppl 91:1-59.

30. Broide DH. Immunomodulation of allergic disease. Annu Rev Med. 2009;60:279-291.

31. Kopp MV, Hamelmann E, Zielen S, et al; DUAL study group. Combination of omalizumab and specific immunotherapy is superior to immunotherapy in patients with seasonal allergic rhinoconjunctivitis and co-morbid seasonal allergic asthma. Clin Exp Allergy. 2009; 39(2):271-279.

32. Remitz A, Virtanen HM, Reitamo S, Kari O. Tacrolimus ointment in atopic blepharoconjunctivitis does not seem to elevate intraocular pressure. Acta Ophthalmol. 2010 Jan 8 [Epub ahead of print].

33. Chen SL, Yan J, Wang FS. Two topical calcineurin inhibitors for the treatment of atopic dermatitis in pediatric patients: a meta analysis of randomized clinical trials. J Dermatolog Treat. 2010;21(3):144-156.

34. Ebihara N, Ohashi Y, Uchio E, et al. A large prospective observational study of novel cyclosporine $0.1 \%$ aqueous ophthalmic solution in the treatment of severe allergic conjunctivitis. J Ocul Pharmacol Ther. 2009;25(4):365-372.

35. Ohashi Y, Ebihara N, Fujishima H, et al. A randomized, placebocontrolled clinical trial of tacrolimus ophthalmic suspension $0.1 \%$ in severe allergic conjunctivitis. J Ocul Pharmacol Ther. 2010;26(2): 165-174.

36. Kari O, Haahtela T. Conjunctival eosinophilia in atopic and non-atopic external eye symptoms. Acta Ophthalmol (Copenh). 1992;70(3): 335-340. 
37. Ponikaus JU, Sherris DA, Kephart GM, et al. Features of airway remodeling and eosinophilic inflammation in chronic rhinosinusitis: is the histopathology similar to asthma? J Allergy Clin Immunol. 2003; 112(5):877-882.

38. Walker C, Bauer W, Braun RK, et al. Activated T cells and cytokines in bronchoalveolar lavages from patients with various lung diseases associated with eosinophilia. Am J Respir Crit Care Med. 1994;150(4): $1038-1048$.
39. Kari O. Atopic conjunctivitis. A cytologic examination. Acta Ophthalmol (Copenh). 1988;66(4):381-386.

40. Feser A, Mahler V. Periorbital dermatitis: causes, differential diagnoses and therapy. J Dtsch Dermatol Ges. 2010;8(3):159-166.

\section{Publish your work in this journal}

The Journal of Asthma and Allergy is an international, peer-reviewed open-access journal publishing original research, reports, editorials and commentaries on the following topics: Asthma; Pulmonary physiology; Asthma related clinical health; Clinical immunology and the immunological basis of disease; Pharmacological interventions and

Submit your manuscript here: http://www.dovepress.com/journal-of-asthma-and-allergy-journal new therapies. Issues of patient safety and quality of care will also be considered. The manuscript management system is completely online and includes a very quick and fair peer-review system, which is all easy to use. Visit http://www.dovepress.com/testimonials.php to read real quotes from published authors. 